\title{
PROPOSAL FOR A SIGNAL FREE JUNCTION AT KUNDALAHALLI GATE JUNCTION
}

\author{
K.V.R.Prasad ${ }^{1}$, Sreenatha.M², Sanjeev Raju.S ${ }^{3}$, Ajay M.D ${ }^{4}$ \\ ${ }^{1}$ Associate Professor, Department of Civil Engineering, Sir M.VIT Bangalore \\ ${ }^{2}$ Assistant Professor, Department of Civil Engineering, Sir M.VIT Bangalore \\ ${ }^{3}$ Student 8th Semester (B.E. Civil), Department of Civil Engineering, Sir M. VIT Bangalore \\ ${ }^{4}$ Student 8th Semester (B.E. Civil), Department of Civil Engineering, Sir M. VIT Bangalore
}

\begin{abstract}
Bangalore is the capital of Karnataka and is the fifth largest city in the country and it is growing at a higher rate than other cities in India. Due to Revolution in IT sector, so it attracts more migrants towards city, thus it requires developed roads, grade separators, subways, mass transit systems etc. In Bangalore city on an average, 2 major \& 2 minor junctions exists for every kilometer of road length, Due to which increase in travel time, frequent bottlenecks and break downs occur and also delay and congestion beyond the traffic management control. Existing infrastructure of road networks in Bangalore is overcrowded and to ease traffic related problems, Since ORR (outer ring road) were constructed, but now traffic on ORR is reached the saturated level
\end{abstract}

Keywords - Traffic; Congestion; ORR; Road networks; Delays

\section{INTRODUCTION}

Kundalahalli Gate junction is located about $1.5 \mathrm{~km}$ away from Marathahalli junction, it is a four legged intersection with arms leading towards Marathahalli, Varthur road, Whitefield road, Shiridi Sai layout and it has lot of delay and queue length during office/school/college hours reaching more than $2000 \mathrm{PCU} / \mathrm{hr}$ during peak hours. BBMP proposed a signal free corridor along Vellara Junction to Hope Farm junction. The $17.5 \mathrm{~km}$ corridor project was started during 2015-16 with its Phase-1 consisting of three major junctions. The 109 crore project got affected at one of the junction - Kundalahalli which was supposed to have an underpass. The problem faced was majorly land acquisition. In addition, the plan is dropped because the land could not be acquired.

The major objective of this study is to give an alternative and long-term solution for the improvement of the present condition by concept of "Partial Land Acquisition" and "Congestion-Free" corridor rather than "signal free corridor".

Some of the objectives of this study are

1. To identify the various proposals to reduce travel time and queue length

2. To provide best proposal at reduced land acquisition

3. To conduct the classified volume studies and turning movements

4. To conduct speed studies

5. To arrive with a best proposal to reduce traffic congestion, delay and queue length.

6. To provide higher level of service

In 2009-10, BBMP took an initiative of providing a signal free corridor along Vellara Junction to 'Hope Farm'
Junction. The $17.5 \mathrm{~km}$ corridor project was started during 2015-16 with its Phase-1 consisting of three major junctions. The 'Rs.109 crore' project got affected at one of the junction - Kundalahalli which was supposed to have an underpass. The problem faced was majorly land acquisition. It required a whooping 6543 sq.m of land which itself would fetch BBMP. The market value is in the range of Rs.5000 to Rs. 15000 per sq.ft, which alone adds up to 35.22 crores. Due to the above-mentioned problem, BBMP has dropped the construction of the underpass in that location $\left(12^{\circ} 57^{\prime} 21.7^{\prime \prime} \mathrm{N}, 77^{\circ} 42^{\prime} 53.4^{\prime \prime} \mathrm{E}\right)$. In this report, an alternative proposal and other effective solutions are mentioned to face the current situation and to provide its serviceability to its design period.

\subsection{Physical Details}

This junction is located about $1.5 \mathrm{~km}$ from Marathahalli junction. This is a typical 4 legged junction. The 4 arms are briefed below

1) Arm towards Marathahalli Junction

It is a road with bi-directional (two way) movement with the central median of varying width of 0.5 to 0.9 $\mathrm{m}$. The carriageway along this stretch varies between $21 \mathrm{~m}$ and $22 \mathrm{~m}$ near the junction whereas the ROW of this road varies between 25 to $27 \mathrm{~m}$ near the junction. The gradient is slop away from the junction. Thickly developed residential and commercial establishments are present on either side of this stretch of road.

2) Arms towards Varthur Road

This part of the road is bi-directional flow of traffic. It has a central median of varying width of 0.5 to $1.15 \mathrm{~m}$. The carriage width is varying between $18 \mathrm{~m}$ to $20 \mathrm{~m}$. Whereas, the ROW is between $27 \mathrm{~m}$ to $28 \mathrm{~m}$. The gradient is sloping towards the junction. Thickly 
developed residential and commercial establishments are present on either side of this stretch.

3) Arm towards ITPL / Whitefield road

This part of the road is divided into bi-directional flow of traffic. It has a central median of varying width of 0.5 to $0.85 \mathrm{~m}$. The carriage width is varying between $21 \mathrm{~m}$ to $22 \mathrm{~m}$. Whereas the ROW of this road is between $28 \mathrm{~m}$ to $30 \mathrm{~m}$. The gradient is sloping towards the junction. Thickly developed residential and commercial establishments are present on either side of this stretch.

4) Arms towards Shirdi Sai Layout

An undivided road is unidirectional. The width of carriageway of this stretch is varying between $6.5 \mathrm{~m}$ to $7 \mathrm{~m}$ and ROW of this road is between $11 \mathrm{~m}$ to $14 \mathrm{~m}$. This stretch is well-developed Residential and commercial establishments on either side.

BBMP Proposal of the 109 crore project was as given below;

Following are the salient features of the underpass at Kundalahalli Gate Junction as proposed by BBMP

- Length of Underpass- 311.14m

- Number of lanes- 4 lanes divided bi-directional
- Vertical clearance- $5.5 \mathrm{~m}$

- Carriageway width- $7.5 \mathrm{~m} \mathrm{X} 2$

- Length of covered portion- $50 \mathrm{~m}$

- $\quad$ Ruling gradient- 5\% (1 in 20)

- Length of approach ramp towards Varthur- $158.4 \mathrm{~m}$

- Length of approach ramp towards Marathahalli - $102.74 \mathrm{~m}$

- $\quad$ Required land acquisition- 6543.70 sq.m

The BBMP plan can be seen in Fig-1 which shows the key features of the previous proposal at the junction showing the part of the land to be acquired.

\section{METHODOLOGY\& ANALYSIS}

As The traffic studies in this junction were done again by us. The studies which were conducted by us are;

- Road Inventories

- Volume studies

- Turning movement studies

- $\quad$ Spot speed studies

- Capacity studies

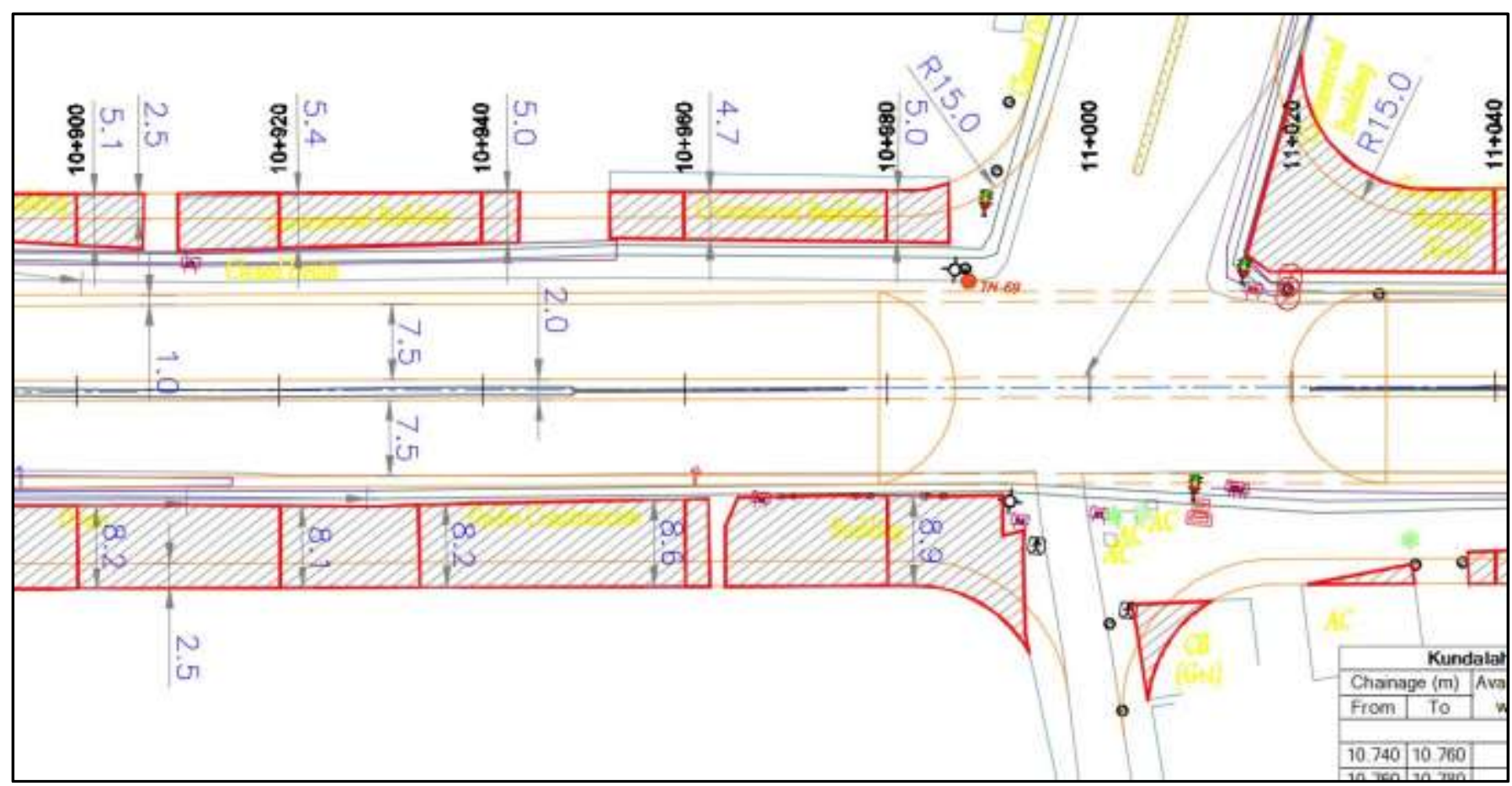

Fig 1 BBMP Proposal (2009)

\subsection{Volume Studies [1]}

The statistics shown below in table-1 were obtained by conducting volume studies using video graph method during peak hours of the junction for a period of 1 week. The average morning and evening PCU is found and shown in the table below. The peak hour volume of the routes is given below.
The above table concludes that there is higher traffic flow along Marathahalli Road - ITPL Road - Varthur Road The previous statistics and the present one is now compared and shown in graph below. Comparison between the old and present traffic conditions shows that there is much higher rate of increase in traffic between "Marathahalli-ITPL". The rate of increase between the routes with high traffic conditions as mentioned above is given in graph below. 
Table 1: Average PCU Values of 2016 studies

\begin{tabular}{|l|l|l|}
\hline Directions & Morning & Evening \\
\hline M-V & 2045.4 & 2416.4 \\
\hline M-I & 1984.4 & 2133.4 \\
\hline I-M & 1412.4 & 1907.8 \\
\hline I-V & 304.4 & 363.6 \\
\hline V-M & 2543.4 & 2133.4 \\
\hline S-M & 163.6 & 219.4 \\
\hline S-I & 333.4 & 244 \\
\hline S-V & 284.8 & 203.4 \\
\hline
\end{tabular}

The above table shows that there is higher rate of increase from Marathahalli to ITPL with an average of $41 \%$ compared with the old traffic data obtained from BBMP during its progress in 2009-10.

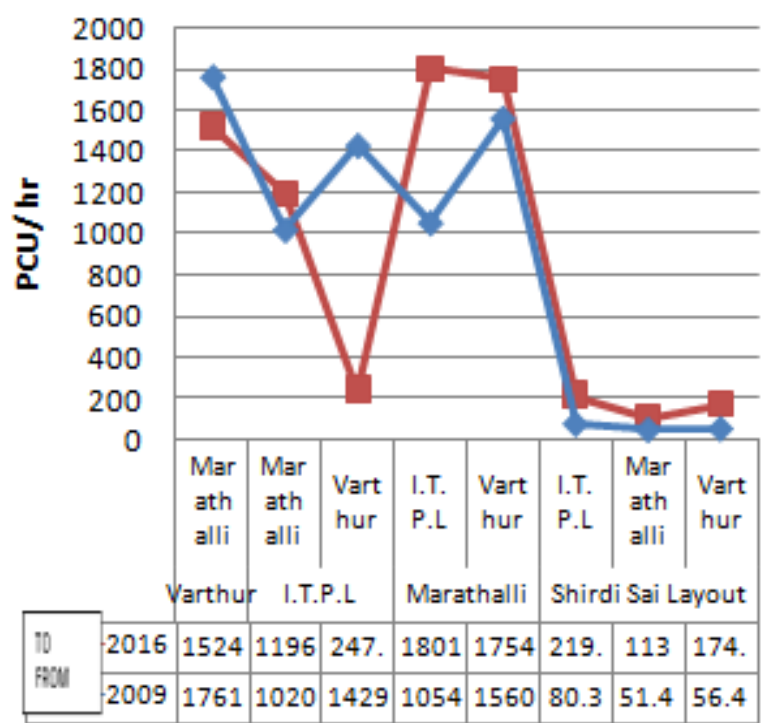

Graph 1 PCU Varation from 2009 to 2016

\section{NEW PROPOSALS [2,3, \& 4]}

Table 2: Rate of Change of PCU between $2009 \& 2016$

\begin{tabular}{|l|l|l|l|}
\hline From & To & Morning & Evening \\
\hline Varthur & Marathahalli & $+07.55 \%$ & $-13.47 \%$ \\
\hline \multirow{2}{*}{ ITPL } & Marathahalli & $+07.57 \%$ & $+14.71 \%$ \\
\cline { 2 - 4 } & Varthur & $-73.17 \%$ & $-82.7 \%$ \\
\hline \multirow{2}{*}{ Marathahalli } & ITPL & $+40.6 \%$ & $+41.5 \%$ \\
\cline { 2 - 4 } & Varthur & $+11.58 \%$ & $+11.07 \%$ \\
\hline
\end{tabular}

For design purposes, the highest PCU obtained in the weekly variation is considered. The values are given below.

Here, we have proposed for an underpass in a curved shape between ITPL and Marathahalli Road. The intension of this proposal is to reduce the land acquisition, use these acquired land in an efficient way, and not leave them unused.

There are two proposals, which are designed considering the IRC specifications. They are
- $\quad$ Proposal A: Two lane bi-directional with each lane of $5.50 \mathrm{~m}$ (i.e. intermediate lane width as per IRC)

- Proposal B: Four-lane road with bi-directional movement with two lanes on either side. Lane width is $3.50 \mathrm{~m}$ each

Note- Both the proposals contains the same geometric design as shown in 4.1 (below) except the width and no. of lanes varies in them.

\subsection{Geometric Design}

- $\quad$ Radius - $130 \mathrm{~m}$

- Length of transition curve - $75 \mathrm{~m}$

- Length of ramp

○ Towards Marathahalli- $125 \mathrm{~m}$

- Towards ITPL $-175 \mathrm{~m}$

- $\quad$ Gradient -

- Towards Marathahalli- 1 in 30

- Towards ITPL -1 in 15

- Both points of transition curve starts at $50 \mathrm{~m}$ from the junction (From Zebra crossing)

\subsection{Land Acquisition}

The land acquisition for the two proposals is reduced in both proposals from 6543.7 sq.m to 2736.95 sq.m and 47380.05sq.m respectively for each proposal. This area can be further be classified in to two types i.e. "full acquisition" for the movement of traffic and "Partial Land Acquisition "in which the land acquired can be used in later stages by the public since it would be unused by the traffic.

At full acquisition, this area is used for traffic movement and pedestrians. This portion of land is fully acquired.

At partial land acquisition, it consists of the slab at ground level below which the traffic movement between Marathahalli- ITPL will be made. Due to which the superstructure cannot be constructed with foundation.

In partial land acquisition, it can be used for small foundation-less structures such as wooden, steel, and other temporary structures such as shops. It can also be used as parking spaces, small market, or as a recreational purposes as parks, etc.

\subsection{Land Acquisition Analysis}

Rate of full acquisition

1. Two lane -9.73 crore $(73 \%$ reduction in cost)

2. Four lane- 17.35 crore $(45.5 \%$ reduction in cost)

Rate of partial acquisition assuming $50 \%$ of its actual market price

1. Two lane -2.51 crore

2. Four lane-3.11crore

Assuming a very low amount of revenue i.e., ₹.10/sq.ft/month from partially acquired land ONLY

1. Two lane proposal - 12 lakhs/annum

2. Four lane proposal - 15 lakhs/annum 
Table 1: Land Acquisition area of the new Proposal

\begin{tabular}{|l|l|l|l|l|}
\hline Proposal & Full $(\mathbf{m} 2)$ & Partial(m2) & Total $(\mathbf{m} 2)$ & \% reduction in area \\
\hline Two lane & 1807.81 & 929.14 & 2736.95 & $58.17 \%$ \\
\hline Four lane & 3224.17 & 1155.88 & 4380.05 & $33.06 \%$ \\
\hline
\end{tabular}

\subsection{Level of Service based on V/C Ratio}

Table 2: LOS Values based on V/C Ratio

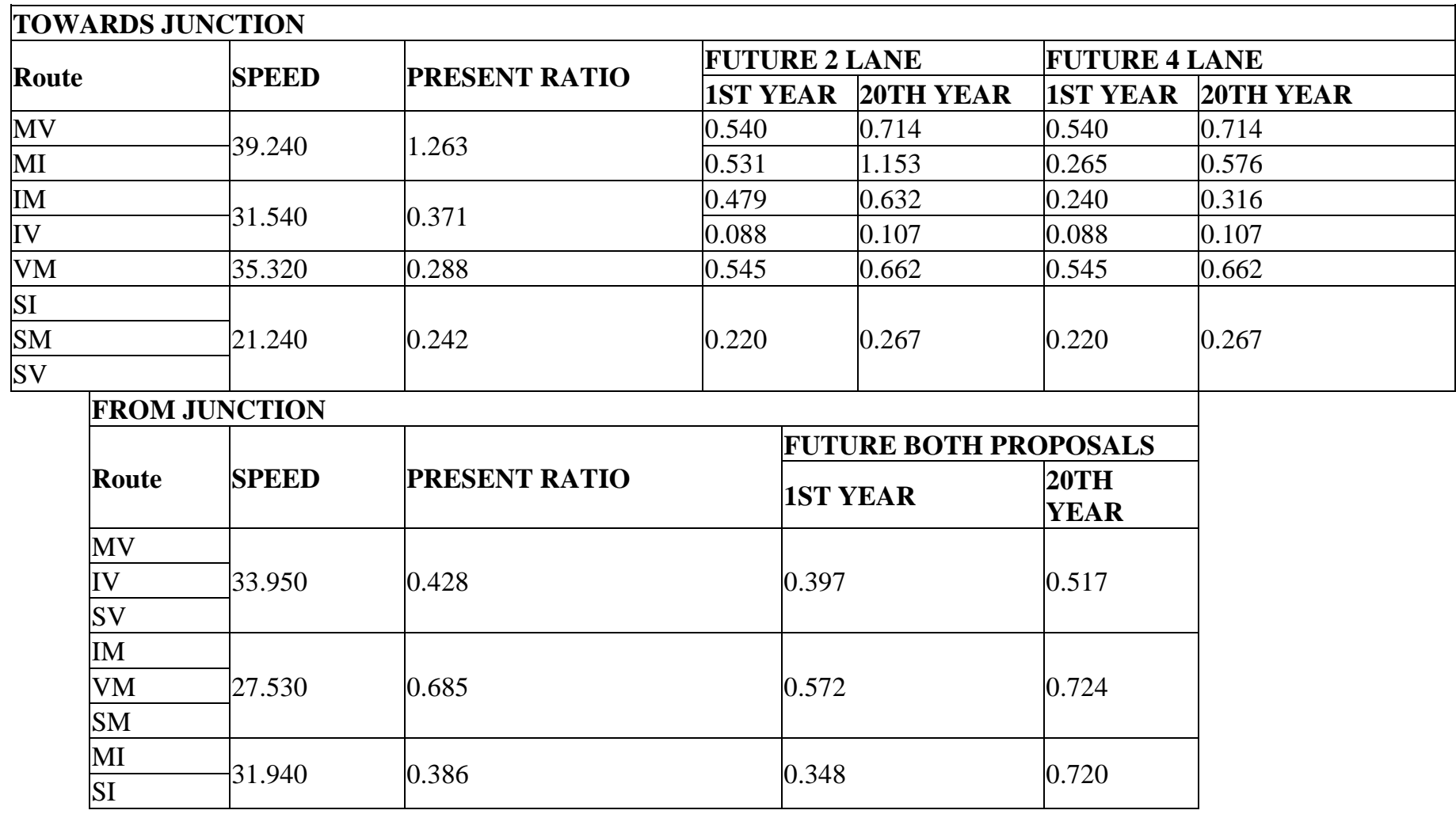

\subsection{Level of Service based on Delay Studies by HCM method [5]}

Table 3: Level of Service based on Delay Studies by HCM method

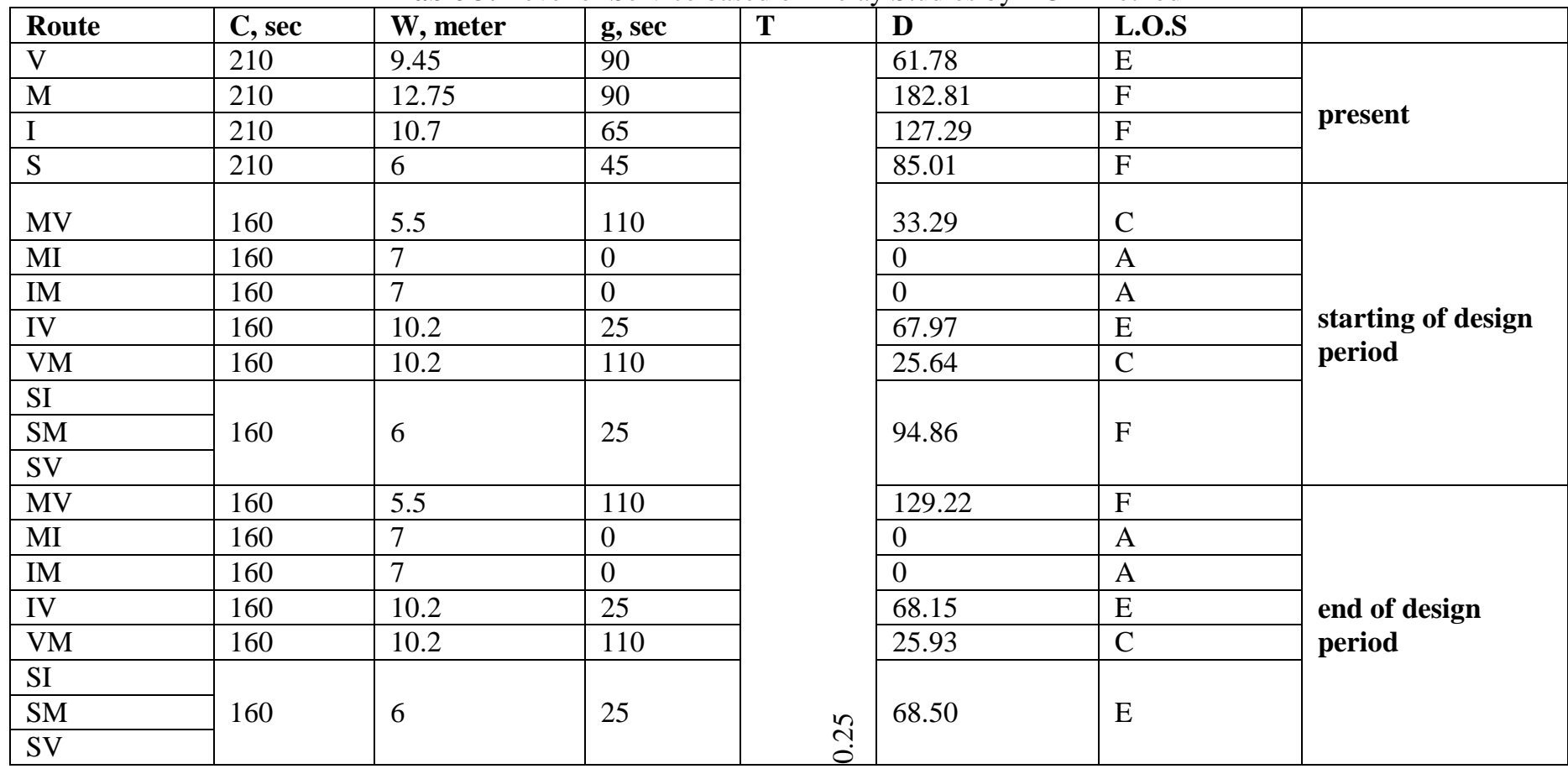




\subsection{Idling Fuel Cost Analysis due to delay ONLY [6]}

Table 4: Idling Fuel Cost Analysis during delay period

\begin{tabular}{|l|l|l|}
\hline Sl. No. & Remarks & Cost of Fuel (₹.) \\
\hline \multicolumn{2}{|l|}{ Fuel Cost for the present condition } & $9736.63 /$ day \\
\hline \multirow{3}{*}{1} & Present Condition & 35.52 lakhs/annum \\
\cline { 2 - 3 } & At the end of 20yrs without providing proposal & 42.022 lakhs/annum \\
\hline \multirow{2}{*}{ Fuel Cost for the Proposal } \\
\hline \multirow{2}{*}{2} & For Proposal & $4999.184 /$ day \\
\cline { 2 - 3 } & Present traffic condition & 18.247 lakhs/annum \\
\cline { 2 - 3 } & & 13356.4 /day \\
\cline { 2 - 3 } & End of design period & 48.75 lakhs/annum \\
\hline & Total cost of fuel during its design life & 6.70 crores \\
\hline
\end{tabular}

\section{CONCLUSION}

With the analysis of obtained data and results and discussions, Following conclusions are drawn. As per the project data analysis we come to two proposals with respect to travel time, queue length, capacity and Level of service (LOS) such as Proposal

1. Proposal-A is having $33.76 \%$ increase the capacity, whereas proposal-B has $14.53 \%$ increase the capacity for existing traffic conditions. Hence the Proposal-A has very good level of service compared to Proposal-B.

2. Proposal-A has $3.5 \mathrm{mt}$ width of 4-lane road bidirectional; hence, the capacity of the road is increased. For proposal-A, requires more land acquisition since it require wider roads, whereas, proposal B requires less land acquisition. Hence Proposal-A is more beneficial in construction and land acquisition.

3. The percentage of area reduction in proposal-A and B is $58.17 \%$ and $33.06 \%$ respectively, has we compared to the previous plan by the BBMP requires more land.

4. Capacity of the roadway will be more at the junction in both the new proposals due to increases in width of the road.

5. Built up/ free space on the top of the underpass-curved portion as mentioned in "partial land acquisition" will gives the area for parking and the amount that collected from parking fee is a reasonable and it is also useful for the minor and regular maintenance.

6. By the construction of Proposal-A, delay can be reduced at the junction along the maximum traffic flowing direction.

7. Proposal-A requires higher land acquisition which in turn increases the partial land acquisition area also. This increases the amount of revenue-generated compare to Proposal-B since it requires lesser partial land acquisition area.

8. Speed of the traffic flow will increase from an average of $30 \mathrm{kmph}$ at present to nearly $50 \mathrm{kmph}$, which gives the most economical speed for vehicles to move, so as it requires lesser/reasonable quantity of fuel consumption has being achieved and also travel time decreases for the road users.

\section{REFERENCES}

[1] IRC-064-1990 - Guidelines for capacity of rural areas

[2] Indian Roads Congress, "Manual for Survey, Investigation and Preparation of Road (IRC:SP:19-292001)

[3] Kadiyali L.R., "Traffic Engineering \& Transport Planning”, Khanna Publishers. Edition-2011.

[4] Khanna \& Justo. "Highway Engineering", Nem Chand \& Bros., Civil lines, Roorkee. Edition-2010.

[5] Highway Capacity Manual-2000

[6] Fuel Wastage and Emssion Due to Idling of Vehicles at Road Traffic Signals- K P Tiwari, R.N Singh, J.B Balwanshi - Volume: 02 Issue: 10 | Oct-2013, Available @ http://www.ijret.org Page no.45 